\title{
"NO ASFALTO NÃO TEM VERDE": A ORGANIZAÇÃO DO ESPAÇO AGRÁRIO NO ASSENTAMENTO HORTO DE CAMAQUÃ, IPEÚNA-SP
}

Sibeli FERNANDES ${ }^{1}$

Bianca C. BORTOLIN ${ }^{2}$

Matheus H. GONÇALVES ${ }^{3}$

\section{Resumo}

Este artigo parte de um estudo de caso realizado no assentamento Horto de Camaquã, no município de Ipeúna/SP. Observamos que este local apresenta peculiaridades em seu território e possui paisagens naturais como grutas e cachoeiras, faz parte do conjunto de municípios que formam a Serra do Itaqueri, possuindo potencial turístico. O levantamento de dados de campo compreendeu a elaboração, teste e aplicação de formulários (semiestruturados) junto a 38 famílias assentadas tendo como objetivo caracterizar quem é o agricultor que está no campo ipeunense, como e o que produz.

Palavras-chave: Agricultura Familiar. Assentamento Horto do Camaquã. Ipeúna/ SP.

\section{Abstract \\ "Asphalt does not have green": the organization of the agrarian space in the Settlement Horto de Camaquã'rs, Ipeúna-SP}

This article is a piece of the research about the Horto do Camaquã'rs rural settlement in the municipality of Ipeúna/SP. In this place can be observed peculiarities, natural landscapes with caves and waterfalls, which are common with the set of municipalities that form the Serra do Itaqueri, a area with a grat tourist potential. The field data collected comprised with a preparation, testing and application of forms (semistructured) with 38 families settled, this has the objective of characterizing the ipeunense farmer how and what they produces.

Key words: Family Farming. Horto do Camaquã'rs rural settlement. Ipeúna/SP.

\footnotetext{
1 Doutoranda em Geografia pela UNESP, Campus de Rio Claro. Bolsista CAPES. E-mail: sibelifernandes@gmail.com

2 Bolsista PIBIC/CNPq, Acadêmica do curso de Geografia, UNESP, Campus de Rio Claro. E-mail: biabortolin@gmail.com

3 Bolsista PROEX, Acadêmico do curso de Geografia, UNESP, Campus de Rio Claro. E-mail: matheus.henrique1997@hotmail.com.br
} 


\section{INTRODUÇÃO}

O presente trabalho apresenta dados preliminares referentes à organização do espaço rural no assentamento Horto de Camaquã, localizado no município de Ipeúna$\mathrm{SP}$, sendo que este estudo faz parte de um projeto de pesquisa maior intitulado "Multifuncionalidade na Organização do Espaço pela Agricultura Familiar". Diante disso, sabe-se que esse município apresenta algumas peculiaridades em seu território, dos quais podemos elencar: predomínio da monocultura canavieira praticada em moldes convencionais, trazendo como consequência uma paisagem não diversa ("mar de cana"), além de uma pecuária pouco desenvolvida; estrutura fundiária na qual dominam as pequenas propriedades; existência do Centro de Pesquisa Mokiti Okada ${ }^{5}$ CPMO; o poder público no município têm programas ligados ao desenvolvimento rural sustentável como a feira de agricultores familiares e produtos naturais que ocorre uma vez por mês; nomeação de "Capital Nacional da Agricultura Natural"6.

Além destes aspectos Ipeúna está localizada em área urbano industrial, mantendo em seu território atividades industriais de significado econômico na área da metalurgia, agroindústria de frangos, aviação civil, entre outras. A partir disso, questiona-se qual o modelo de organização do espaço rural que prevalece nesse município? É possível encontrar-se o modelo de organização de agricultura familiar em espaços dominados pelo urbano-industrial? A presença majoritária das pequenas propriedades no território municipal indicaria a existência de agricultura familiar?

A partir desses questionamentos entendemos que mesmo dentro de um espaço dominado pela produção moderna, representado pela monocultura canavieira e pela atividade pecuária, além da presença de indústrias de representatividade nacional, é possível encontrarmos a lógica de organização familiar nas pequenas propriedades existentes, tendo em vista que o processo de ocupação do município esteve diretamente associado à tradição agrícola com base no trabalho familiar.

O levantamento de dados de campo compreendeu a elaboração, teste e aplicação de formulários ${ }^{7}$ (semiestruturados) junto aos produtores rurais, tendo como objetivo caracterizar quem é o agricultor que está no campo ipeunense, como e o que produz.

\section{CARACTERIZANDO OS AGRICULTORES FAMILIARES: ANÁLISE PRELIMINAR DOS DADOS DE CAMPO}

Objetiva-se apresentar, por meio dos dados preliminares da pesquisa de campo, o modelo de organização dos agricultores familiares assentados de reforma agrá$\mathrm{ria}^{8}$, identificando a presença da lógica familiar, elencando o potencial produtivo,

\footnotetext{
${ }^{4}$ Coordenado pela Profa Dra Darlene Ap. de O. Ferreira.

5 CPMO tem como objetivo pesquisar, estudar, assessorar e desenvolver projetos de pesquisa e desenvolvimento com base nos princípios, conceitos e práticas da Agricultura Natural, modelo agrícola sustentável de base agroecológica, ver mais em: http://www.fmo.org.br/mokiti-okada/ ou http://www.cpmo.org.br/

6 Ipeúna sancionou lei municipal no 1228, de 26 de novembro de 2015, que nomeia o município como "Capital da Agricultura Natural" a qual criou a "Comissão Municipal da Agricultura Natural", órgão paritário encarregada de planejar as ações que visem a promoção da Agricultura Natural.

7 O formulário possui 98 questões, para este artigo selecionamos 22 questões.

8 Até o momento da pesquisa o levantamento de dados de campo ocorreu no recorte espacial do Assentamento Horto do Camaquã, localizado na porção nordeste de Ipeúna.
} 
paisagístico, turístico e cultural através da abordagem sistêmica proposta por Diniz (1984), analisando principalmente os elementos internos e externos do sistema da agricultura.

As propriedades no assentamento seguem um padrão de organização (Figura 1): as porteiras ficam a poucos metros das casas de alvenaria, que são cercadas por hortas, pequenos jardins com árvores frutíferas, poços artesianos, pocilgas e cachorros e galinhas criados soltos.

O conjunto familiar encontrado tem as seguintes características: número médio de integrantes da família é 3 membros, a população rural está na faixa de idade entre 30 a 60 anos, a maioria dos moradores são homens, com baixa escolaridade, comentam ter cursado até o $5^{\circ}$ ano do ensino fundamental. Das 38 famílias entrevistadas, 22 responderam que algum membro da família recebe aposentadoria.

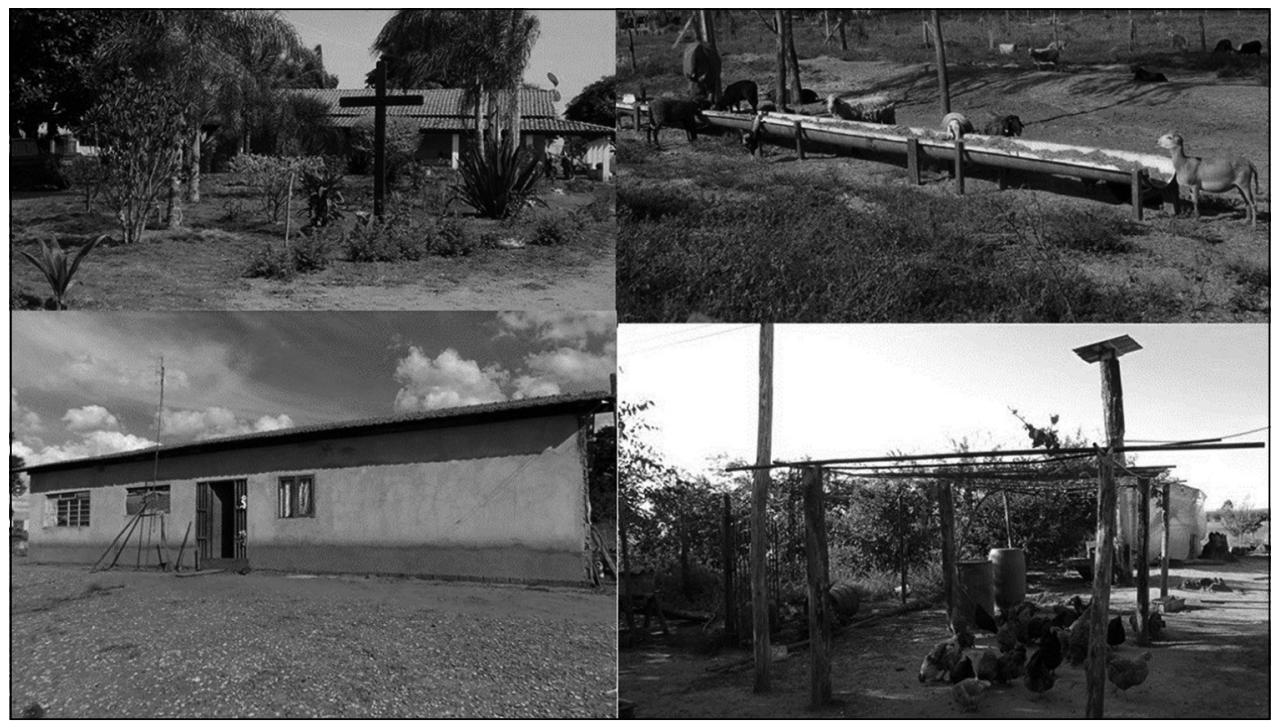

Figura 1 - Casas e criações

Fonte: Pesquisa de Campo, abril e maio 2017.

O assentamento possui 38 propriedades rurais, os tamanhos dos lotes individuais variam entre 14 hectares e 17,5 hectares. Quanto à forma como foram adquiridas as propriedades, do total de entrevistados, 22 conseguiram seus lotes através da compra da benfeitoria, 16 obtiveram suas terras através do cadastro do ITESP Instituto de Terras do Estado de São Paulo.

Ao analisar os dados da forma de obtenção do lote e quanto tempo a propriedade pertence à família (Quadro1), percebe-se que existe uma constante mudança de moradores, uma vez que esses realizam a venda da benfeitoria. Somente oito entrevistados estão no assentamento entre 18 a 20 anos, ou seja, desde o seu processo de ocupação e consolidação como beneficiários de reforma agrária. 


\section{Quadro 1 - Tempo que a propriedade pertence à família}

\begin{tabular}{|c|c|}
\hline Período & Frequência \\
\hline Até 1 ano & 4 \\
\hline De 2 a 5 anos & 4 \\
\hline De 6 a 9 anos & 11 \\
\hline De 10 a 13 anos & 8 \\
\hline De 14 a 17 anos & 3 \\
\hline De 18 a 20 anos & 8 \\
\hline
\end{tabular}

Fonte: Trabalho de campo - abril a maio de 2017.

Processos que reorganizam as formas de uso e apropriação da terra, também inserem, no território, atores sociais que estavam excluídos do acesso à terra, outros que às vezes não possuem relação com tradições agrícolas, demonstrando que para alguns o assentamento garante, antes de mais nada, um local de moradia. Essas características revelam que para muitos dos proprietários dos lotes não há uma preocupação com a sua continuidade entre os membros do grupo familiar, sendo que muitos filhos, apesar de morarem na propriedade, já exercem atividades na cidade.

Ao serem questionados sobre a principal atividade do proprietário, constatamos que 17 entrevistados se dedicam a pecuária (gado leiteiro e gado de corte), 11 à agricultura e pecuária9 ${ }^{9}$, oito exclusivamente à agricultura, com destaque à produção de hortaliças, mandioca, legumes, frutas, café, cana-de-açúcar (para a alimentação das criações), milho e vassoura caipira e dois dedicam-se à silvicultura. Um dos entrevistados relatou que, além de dedicar-se a agricultura, dedica-se à produção de carvão; outro agricultor, além de dedicar-se à pecuária desenvolve atividade nãoagrícola (fabricação de produtos de limpeza, sem autorização da vigilância sanitária), estas atividades complementam a renda familiar.

Referente às atividades desenvolvidas na propriedade (Quadro 2), 36 dos entrevistados dedicam-se à agricultura e pecuária destes, 6 realizam beneficiamento de alguns produtos, dois não realizam nenhuma atividade. Deve-se salientar que as condições físicas do assentamento são precárias, ocorrendo a presença de tocos de eucalipto e falta de água potável em muitos lotes.

Atividades turísticas, de lazer ou esportes de aventura não aparecem nessa área do município. Sabe-se que Ipeúna possui demanda turística real e potencial graças às paisagens naturais (cuesta ${ }^{10}$ de São Pedro, figura 2), como grutas e cachoeiras, fazendo parte do conjunto de municípios que formam a Serra do Itaqueri. É necessário indicar que a área do assentamento, antiga área de eucalipto utilizada pela antecessora Companhia Paulista de Estradas de Ferro, possui terreno movimentado e possui baixo indicativo de fertilidade.

Sem essa alternativa, os assentados procuram transformar e agregar valor ao que produzem. Quando questionados se existe o processamento, mesmo que artesanal, de algum produto (Quadro 3) 22 entrevistados responderam não e 16 afirmaram realizar o processamento artesanal, com destaque ao beneficiamento de queijos,

92 entrevistados responderam que estão sem produção até o momento porque moram no assentamento a pouco tempo.

10 As cuestas são definidas como uma forma de relevo dissimétrico, composta por uma vertente em declive íngreme de um lado e uma rampa em declive suave no reverso, decorrente da erosão diferencial das rochas. A região da Serra de São Pedro/SP, área de ocorrência de basaltos jurocretáceo (topo da escarpa) e arenitos eólicos (escarpa e glacis) do Triássico ao Cretáceo Médio, consiste em uma das zonas mais típicas das cuestas na Bacia do Paraná. (PINHEIRO, 2014) 
linguiças e doces. No entanto, não são todos os entrevistados que comercializam seus produtos, ou seja, o beneficiamento é somente para o autoconsumo familiar.

\section{Quadro 2 - Tipos de atividades desenvolvidas nas propriedades}

\begin{tabular}{|c|c|}
\hline Atividade & Frequência \\
\hline Agricultura e Pecuária & 36 \\
\hline Beneficiamento/agroindústria familiar & 6 \\
\hline Sem Produção & 2 \\
\hline Turismo/Esporte/Lazer & 0 \\
\hline
\end{tabular}

Fonte: Trabalho de campo - abril a maio de 2017.

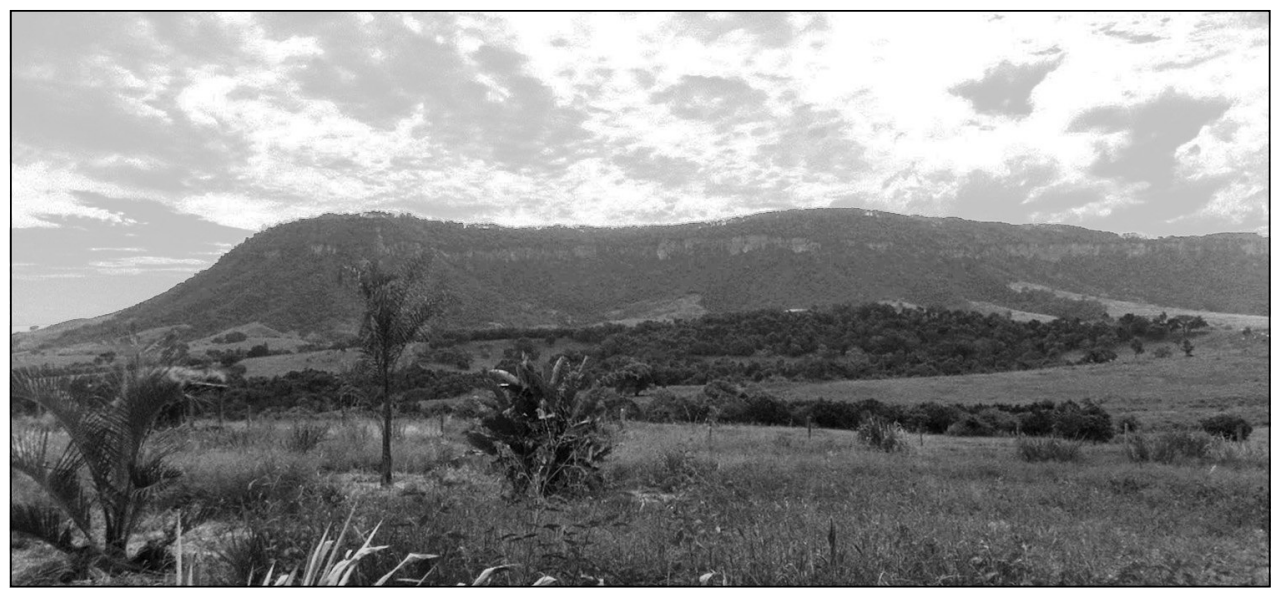

Figura 2 - Cuesta de São Pedro, Ipeúna

Fonte: aplicação de formulário teste, março de 2017.

Quadro 3 - Frequência das propriedades com processamento de produtos

\begin{tabular}{|l|l|}
\hline Não & 22 \\
\hline Sim & 16 \\
\hline Produto & Frequência \\
\hline Queijo & 13 \\
\hline Linguiça & 4 \\
\hline Doce & 2 \\
\hline Cachaça & 0 \\
\hline Outros & \\
Produto de Limpeza & 1 \\
Vassoura Caipira & 1 \\
Pão & 1 \\
Só para autoconsumo & 2 \\
\hline
\end{tabular}

Fonte: Trabalho de campo - abril a maio de 2017. 
Para conhecer como se organiza a produção dos agricultores familiares, indagou-se sobre a atividade que gera mais renda para as famílias assentadas. O destaque é para a pecuária com gado de corte (11 entrevistados), venda de leite in natura (sete entrevistados), leite e queijo (seis), galinha caipira e hortaliças (cinco entrevistados), venda de criações como suínos, ovinos e caprinos (cinco entrevistados), sendo que os demais (quatro entrevistados) citaram, ovos caipiras, banana, milho, cana de açúcar e a vassoura caipira.

Quando questionados há quanto tempo se dedicam à essas atividades (figura 3, agricultura e pecuária), a maioria dos entrevistados (13) respondeu que se dedica há mais de cinco anos. Entretanto, deve-se considerar que esse conjunto de produtores está no assentamento há mais tempo, conforme pudemos assinalar anteriormente (Quadro 1).

Não sabe/não respondeu

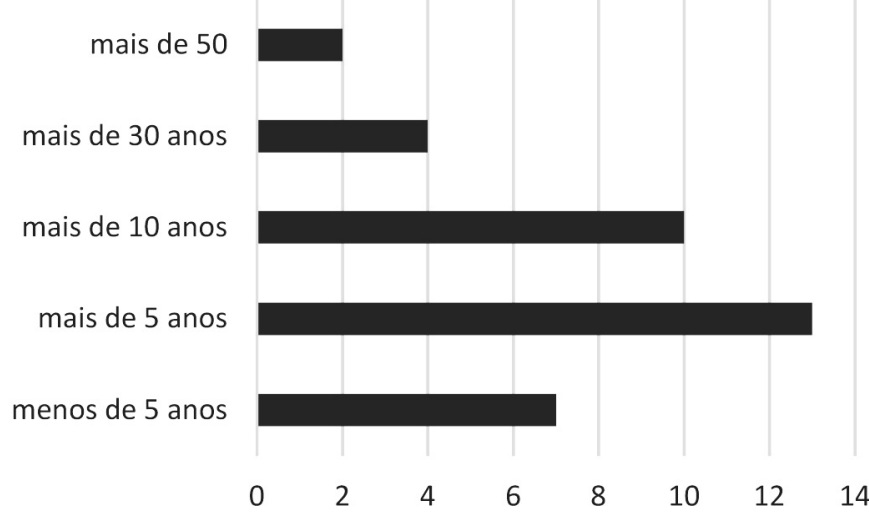

Figura 3 - Tempo de dedicação à agricultura e pecuária

Fonte: Trabalho de campo - abril a maio de 2017.

mais de 5 salários mínimos

de 3 a 5 salários mínimos

de 2 a 3 salários mínimos

até 1 salário minimo
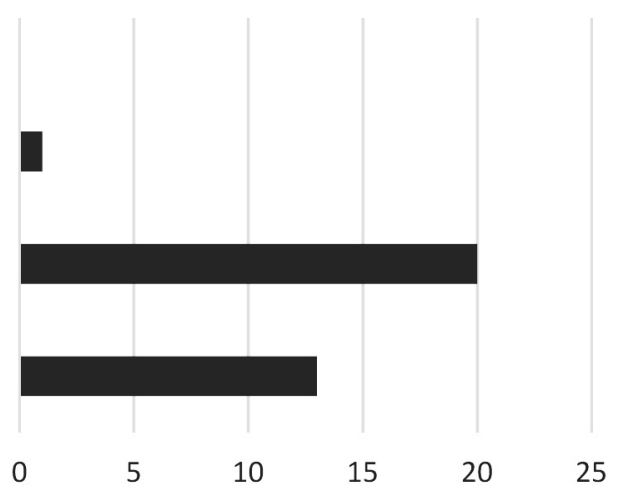

Figura 4 - 0 total da renda mensal é de quantos salários mínimos*

* (SM a partir de 1/01/2017: R\$937,00)

Fonte: Trabalho de campo - abril a maio de 2017. 
Questionamos sobre a renda mensal dos entrevistados (Figura 4) e do total 20 relataram que recebem entre dois e três salários, 14 agricultores recebem mensalmente até um salário, dois recebem entre três a cinco salários mínimos e dois entrevistados não responderam. Percebemos que alguns dos entrevistados ficaram desconfortáveis em responder essa questão.

A produção de leite (Figura 5) se constitui em uma atividade básica para grande parte dos agricultores familiares. Na área pesquisada, o leite é uma das atividades que mais gera renda, na percepção de Silva Neto; Basso (2005) a gestão da produção leiteira familiar é um elemento favorável para o aumento da renda, pois a venda do leite in natura é garantida anualmente.

A produção de leite, além de possuir um potencial para a agregação de valor por unidade de área, é uma atividade que pode se adaptar à diferentes situações ecológicas e socioeconômicas, o que permite que ela seja viável a partir de diferentes escalas e sistemas de produção (SILVA NETO; BASSO, 2005).

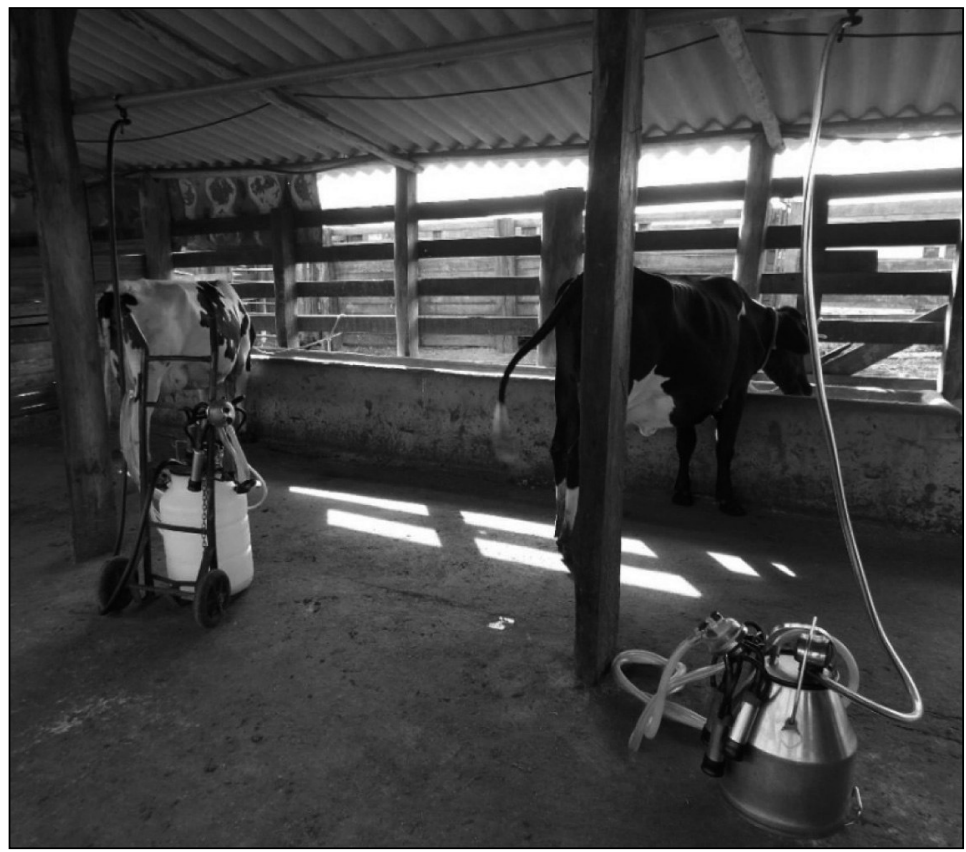

Figura 5 - Vacas prontas para a ordenha

Fonte: Trabalho de campo - abril a maio de 2017.

Buscando ainda um perfil cultural dos entrevistados, a partir desse momento as questões referem-se a visão de mundo que eles têm "de si para aos outros", indagamos sobre aspectos políticos, associativos (Figura 7 e 8), sucesso e função da agricultura (Quadro 4 e 5), prioridade dos investimentos (Quadro 6), venda das terras (Quadro 7) e a dificuldade em morar no campo (Quadro 8).

Nos casos estudados constatamos que o noticiário sobre o meio rural é acompanhado com frequência por mais da metade dos entrevistados (20), 14 responderam que acompanham de vez em quando, quatro não assistem notícias sobre o meio 
rural, 25 entrevistados não tem a prática da associatividade, 10 são associados a cooperativas, apenas quatro dos entrevistados são associados do sindicato rural de Rio Claro/SP e quatro são filiados à partidos políticos (figura 7). Porém, quando perguntamos se era importante aos agricultores estarem organizados em associações ou cooperativas para obter benefício na compra de insumos, maquinários, assistência técnica, comercialização da produção, etc., a maioria (34) respondeu que é importante.

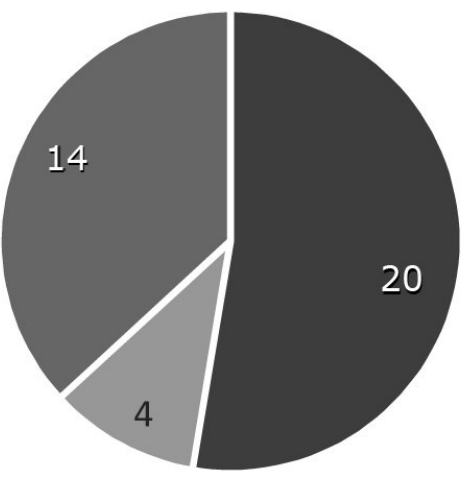

- sim não nde vez em quando

\section{Figura 6 - Frequência de acompanhamento} de noticiário sobre o meio rural

Fonte: Trabalho de campo - abril a maio de 2017.

\section{Associado a:}

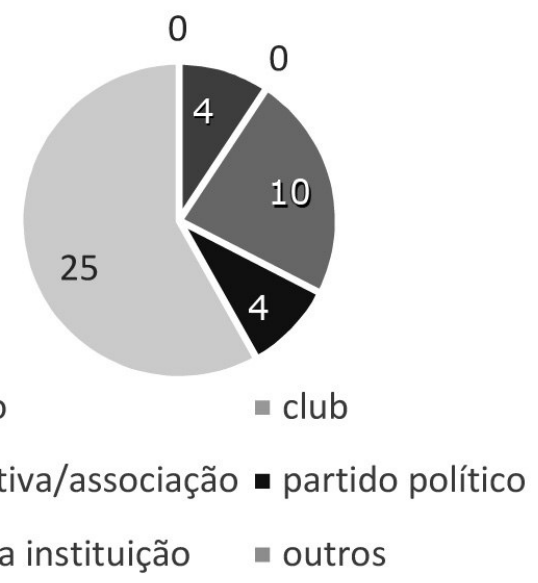

Figura 7 - Tipos de associação institucional

Fonte: Trabalho de campo - abril a maio de 2017. 


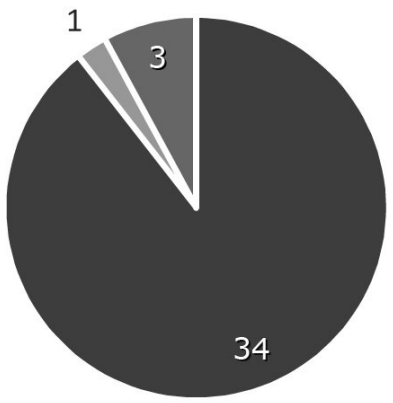

- Sim - Não - Não sabe responder

Figura 8 - Importância da organização em associação

Fonte: Trabalho de campo - abril a maio de 2017.

Uma outra questão procurou saber o ponto de vista dos entrevistados em relação aos aspectos que possibilitam o sucesso na agricultura. Quatro respostas se destacaram: trabalhar na própria terra, dispor de sementes e animais de boa qualidade, ter acesso à máquinas para trabalhar e acesso ao crédito rural. Indagados sobre qual seria a função da agricultura hoje, a resposta mais frequente foi a produção de alimentos, seguida da preservação do meio ambiente e manutenção das tradições agrícolas.

Verificamos também qual a prioridade dos entrevistados em caso de lucratividade na produção. Não fugindo ao padrão esperado, em se tratando de pequenas propriedades familiares, as respostas mais frequentes (24 e 14 entrevistados) foram a compra de mais animais ou de maquinários, e em quais situações venderiam suas terras, quatro respostas de destacaram: não venderiam por nenhum motivo, comprariam outra maior em outro lugar, venderiam para ajudar um filho em dificuldade financeira, comprar outras terras melhores, ainda que menores. E para concluir esta parte, perguntamos qual seria o problema em residir no campo, duas respostas destacaramse: não existem problemas e a falta de segurança. A pedido do Conselho de Segurança Municipal - Conseg, constituído devido à crescente insegurança na zona rural, estamos realizando o georreferenciamento das porteiras de todas as propriedades para a elaboração de um mapa com sua localização, incluindo as estradas rurais (principais, vias secundárias e terciárias), conforme mostrado na figura 9.

\section{Quadro 4 - Fatores necessários para ter sucesso na agricultura}

\begin{tabular}{|c|c|}
\hline Respostas & Quantidade \\
\hline Trabalhar na própria terra & 36 \\
\hline Dispor de sementes e animais de boa qualidade & 35 \\
\hline Ter acesso a máquinas para trabalhar & 34 \\
\hline Acesso ao crédito rural & 33 \\
\hline Transformar seus produtos agregando-Ihes mais valor & 31 \\
\hline Ter assistência técnica regularmente & 27 \\
\hline Outros & 1 \\
Facilidade para conseguir acesso ao Pronaf & 1 \\
Chover na hora certa & 1 \\
Acesso ao mercado para venda dos produtos & 1 \\
Apoio maior da sociedade & \\
\hline
\end{tabular}

Fonte: Trabalho de campo - abril a maio de 2017. 
Quadro 5 - Função da agricultura na sociedade hoje

\begin{tabular}{|c|c|}
\hline Respostas & Quantidade \\
\hline Produção de alimentos & 29 \\
\hline Preservação do meio ambiente & 17 \\
\hline Manutenção das tradições agrícolas & 12 \\
\hline Fonte de renda para a família & 9 \\
\hline Outros & 2 \\
\hline
\end{tabular}

Fonte: Trabalho de campo - abril a maio de 2017.

Quadro 6 - Prioridade de investimento em situação de lucratividade

\begin{tabular}{|c|c|}
\hline Respostas & Quantidade \\
\hline Comprar mais animais & 24 \\
\hline Comprar maquinário & 14 \\
\hline Poupança & 4 \\
\hline Comprar mais terras & 3 \\
\hline Comprar veículo & 1 \\
\hline Comprar bens imóveis na cidade & 1 \\
\hline Outros & 1 \\
Manter o sítio estruturado & 1 \\
\hline
\end{tabular}

Fonte: Trabalho de campo - abril a maio de 2017.

\section{Quadro 7 - Fatos que levariam à venda das terras}

\begin{tabular}{|c|c|}
\hline Respostas & Quantidade \\
\hline Não venderia suas terras por nenhum motivo & 15 \\
\hline Comprar outra maior em outro lugar & 12 \\
\hline Ajudar um filho em dificuldade financeira & 12 \\
\hline Comprar outras melhores, ainda que menores & 10 \\
\hline Mudar-se para a cidade e desenvolver outra atividade & 6 \\
\hline Não sabe/Não respondeu & 3 \\
\hline Outros & 1 \\
\hline
\end{tabular}

Fonte: Trabalho de campo - abril a maio de 2017.

\section{Quadro 8 - Problema em se residir no campo hoje}

\begin{tabular}{|c|c|}
\hline Respostas & Quantidade \\
\hline Não tem problema & 19 \\
\hline Violência & 15 \\
\hline Ausência de posto de saúde & 2 \\
\hline Dificuldade de acesso à cidade & 1 \\
Falta de água encanada & 2 \\
Transporte escolar passa longe do sítio & 1 \\
Falta de Transporte público & 1 \\
Condição da estrada & 1 \\
\hline
\end{tabular}

Fonte: Trabalho de campo - abril a maio de 2017. 
PROPRIEDADES RURAIS DO ASSENTAMENTO HORTO DO CAMAQUÃ, IPEÚNA/SP

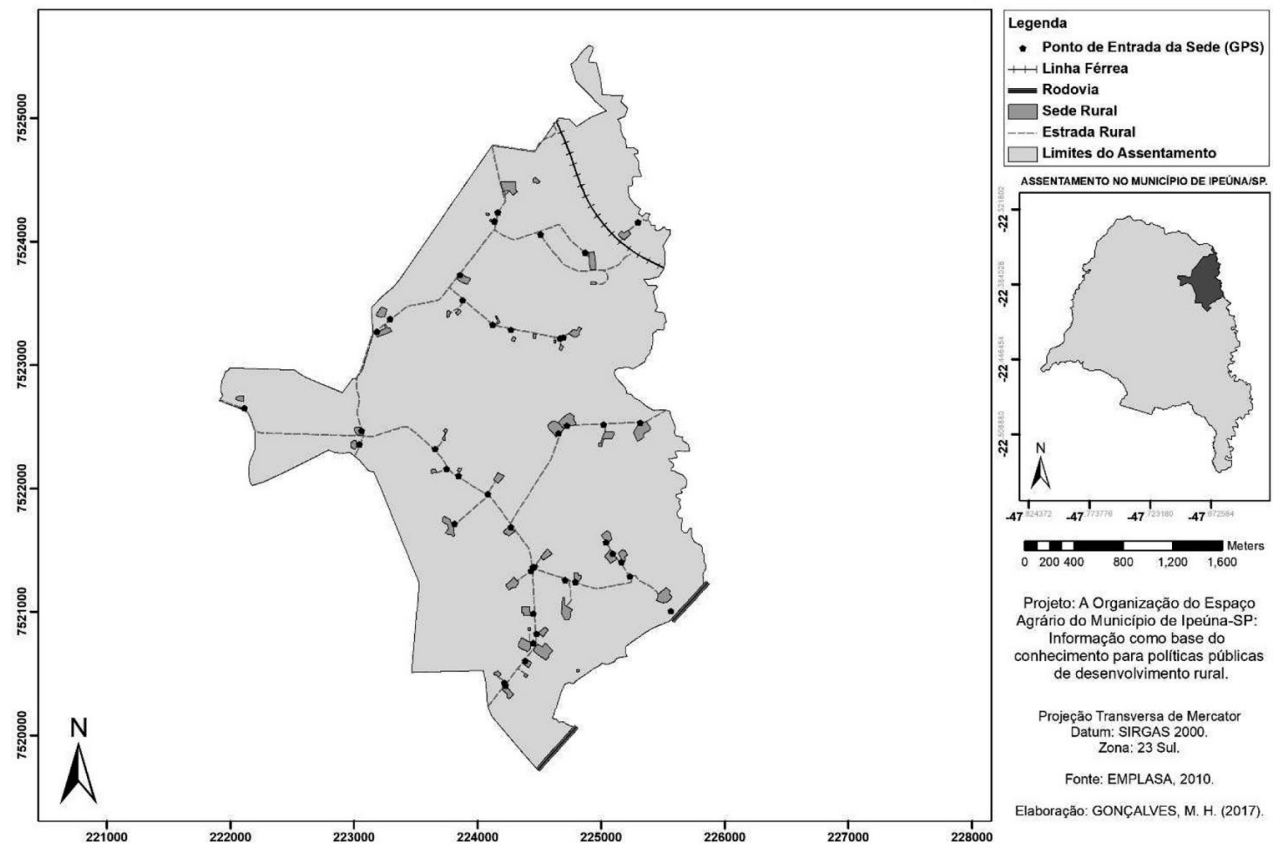

Figura 9 - Propriedades Rurais entrevistadas no Assentamento Horto do Camaquã, Ipeúna/SP

Fonte: Emplasa, 2010

\section{CONSIDERAÇÕES PRELIMINARES}

No debate sobre o futuro da agricultura familiar alguns pensadores e estudiosos do tema asseguravam o desaparecimento da pequena propriedade de caráter familiar e presença hegemônica de empresas agrícolas capitalizadas e produtivas. Essa justificativa encontra-se fundamentada em critérios apenas de caráter econômico, os quais negligenciam elementos de ordem social, cultural e ambiental.

Em linhas gerais podem se estabelecer as seguintes conclusões até o momento para o espectro estudado: as famílias entrevistadas dedicam-se, principalmente, à agricultura e à pecuária; são propriedades pouco mecanizadas; com ausência de assistência técnica e presença do processamento artesanal de queijo. Há uma prevalência de adultos e idosos (30-60 anos), sendo que os idosos indicam a presença de renda complementar nas propriedades, através da aposentadoria rural. A maioria da população é do sexo masculino, com baixa escolaridade. Sobre o perfil cultural dos entrevistados, mais da metade deles assistem, com frequência, noticiários sobre o meio rural. A maioria não tem a prática da associatividade, mas admitem a importância de estarem organizados em cooperativas e/ou associações. Trabalhar na própria terra, dispor de sementes e animais de boa qualidade, ter acesso à máquinas para trabalhar e acesso ao crédito rural foram as condições mais indicadas pelos agricultores para a obtenção de sucesso na agricultura. A função da agricultura hoje para os entrevistados é a produção de alimentos, preservação do meio ambiente e a 
manutenção das tradições agrícolas. A prioridade do investimento em caso de lucratividade é a compra de animais e/ou maquinários, alguns citam que não venderiam a benfeitoria de suas terras por nenhum motivo. E qual seria o problema em residir no campo, duas respostas destacaram-se: não existem problemas e a falta de segurança, uma vez que os assaltos nas propriedades rurais de Ipeúna vêm aumentado.

Devido ao caráter inicial em que se enquadra este artigo, torna-se impossível elaborar, nesse momento, conclusões definitivas à respeito do tema pesquisado, de como responder com precisão qual o modelo de organização do espaço rural que prevalece no município de Ipeúna. O tamanho dos lotes entre 14 e 17 hectares situados no Assentamento, representa espacialmente a possibilidade da lógica e organização da existência da agricultura familiar na porção nordeste do município. Sabemos que o tamanho das propriedades não é o único parâmetro para a análise da agricultura familiar e somente com o conhecimento total das características do território municipal, conseguiremos responder o problema de pesquisa.

\section{REFERÊNCIAS}

ABRAMOVAY, Ricardo. Paradigma do Capitalismo agrário em questão. Editora Hucitec, Editora da Unicamp: São Paulo, 1992.

CHAYANOV, Alexander Vasilievich. Teoria dos sistemas económicos e não capitalistas. Buenos Aires: Ediciones. Nueva Vision, 1974.

DINIZ, José A. F. Geografia da Agricultura. São Paulo: Difel, 1984.

GERARDI, Lucia Helena de Oliveira; SILVA, Barbara-Christine M. Nentwig. Quantificação em Geografia. São Paulo: DIFEL, 1981.

PINHEIRO, Marcos Roberto. Estudo Morfotectônico da Região da Serra de São Pedro e do Baixo Piracicaba/SP. 2014. 293f. Tese (Doutorado Geografia Física) FFLCH, USP, São Paulo. 2014.

SILVA NETO, Benedito; BASSO, David. A produção de leite como estratégia de desenvolvimento para o Rio Grande do Sul. Desenvolvimento em questão. Ijuí, n. 5, ano 3, Editora Unijuí, 2005. 